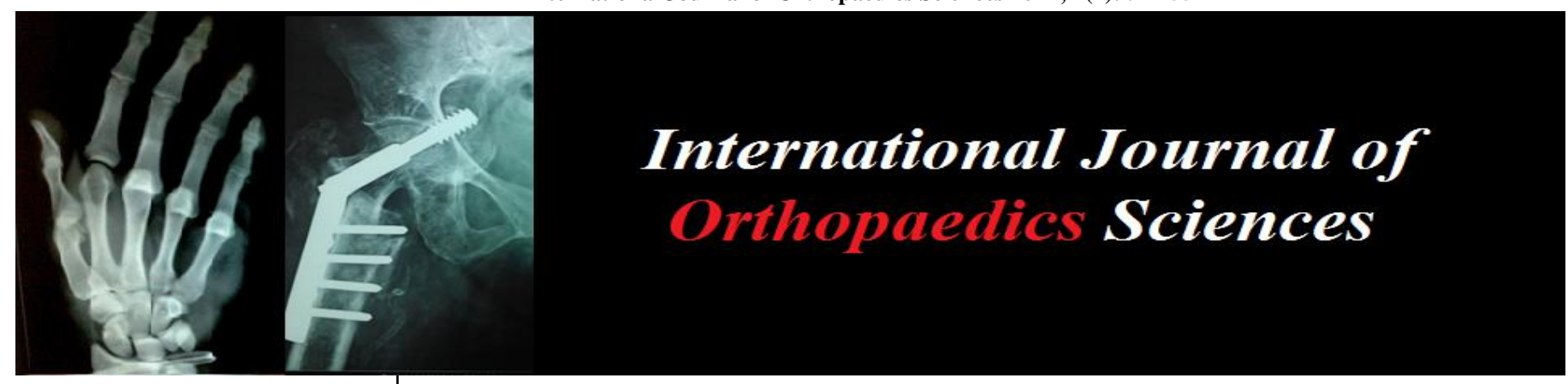

E-ISSN: 2395-1958

P-ISSN: 2706-6630

IJOS 2021; 7(4): 547-551

(C) 2021 IJOS

www.orthopaper.com

Received: 17-08-2021

Accepted: 18-09-2021

Pradeep Pilajirao Kulkarni

Medical Director, Prakash

Institute of Medical Sciences and

Research, Islampur,

Maharashtra, India

Pramod G Kuchekar

Associate professor, Department of Orthopaedics, Prakash

Institute of Medical Sciences and

Research, Islampur,

Maharashtra, India
Corresponding Author: Pramod G Kuchekar

Associate Professor, Department

of Orthopaedics, Prakash

Institute of Medical Sciences and

Research, Islampur,

Maharashtra, India

\section{A Cross-Sectional, descriptive study of bone mineral density in Western Maharashtra}

\section{Pradeep Pilajirao Kulkarni and Pramod G Kuchekar}

DOI: https://doi.org/10.22271/ortho.2021.v7.i4h.2931

\begin{abstract}
Introduction: Osteoporosis and osteopenia form the major bulk of health hazard, almost leading to silent epidemic. In the developing world, the aging population suffer from disability, dependence and osteoporosis. Osteoporosis does not have a dramatic clinical presentation except when fracture results.

Materials and methods: This is a cross sectional descriptive study of 2400 subjects conducted among patients and relatives of patients coming to Gurukrupa Arogyadham, Islampur in the year 2019. BMD evaluation was done by Pronosco Exposure V.2 (DXR Method) using AP X-Ray of non-dominant hand. Statistical analysis was done using SPSS software and results expressed in proportions, mean, standard deviation and $\mathrm{P}$ values from Anova test. The study obtained ethical clearance from IEC committee of Prakash institute of medical sciences and research at Islampur.

Results: Out of 2400 individuals, 928 were having osteopenia. Mean BMD of these individuals was $0.48912 \mathrm{gms} / \mathrm{sq}$. cm. Out of these 2400 individuals, 464 were having osteoporosis. Mean BMD was $0.3988 \mathrm{gms} / \mathrm{sq} . \mathrm{cm}$. As age advances percentage of subjects having normal BMD goes on decreasing and percentage of subjects having osteopenia and osteoporosis goes on increasing. Mean BMD of premenopausal females was more than postmenopausal females.

Conclusion: This study gives appropriate picture of status of bone mineral density among population. We can detect vulnerable population suffering Osteopenia or Osteoporosis and it will be easy to treat those people for the same in advance. Timely diagnosis and appropriate treatment reduce risk of bony fractures as well as economic load on individual person and ultimately on nation.
\end{abstract}

Keywords: Bone mineral density, Osteoporosis, Osteopenia, DXR, Fracture

\section{Introduction}

Osteoporosis and osteopenia form the major bulk of health hazard, almost leading to silent epidemic. In the developing world, the aging population suffer from disability, dependence and osteoporosis. Osteoporosis does not have a dramatic clinical presentation except when fracture results. It is therefore called a 'Silent epidemic' ${ }^{[1]}$. Osteoporosis is a common skeletal disease that is characterized by low bone strength which is reason for reduced Bone Mineral Density (BMD) leading to increased risk of fractures. It has serious clinical consequences and its treatment is costly to individuals and to the society ${ }^{[2]}$. It is important to maintain the quality of life in old age with developing disabilities, among which osteoporosis and its associated fractures are more prevalent. It is estimated that the risk of fragility fractures is 1.7 to 3.5 times more among older individuals ${ }^{[3]}$. In osteoporotic postmenopausal women the stiffness of the aorta, assessed by means of augmentation index and central aortic systolic and pulse pressures was greater than control subjects ${ }^{[4-5]}$. Another large prospective study in women over 65 years old showed that diminished Bone Mineral Density (BMD) at the proximal radius was strongly associated with deaths from stroke and each percentage decrease in BMD was associated with a 1.19 fold increase in mortality, adjusted for age and duration of follow up ${ }^{[4-7]}$.

According to W.H.O. figures one out of eight males and one out of three females in India suffer from Osteoporosis making India one of the largest affected country in the world. Two hundred million people in the world are suffering from Osteoporosis ${ }^{[2]}$. As the life expectancy is increasing even in developing countries, by the year 2035, the maximum number of Osteoporosis cases in the world will be in India \& China ${ }^{[8]}$. It makes it important for these reasons that the bone mineral density data referring to Indian population is available. Considering the lack of studies on osteoporosis and bone mineral density, epidemiology, and 
lack of infrastructure and high risk of hip fractures in Indian population, the present study was taken up in population of western Maharashtra.

A T-score between +1 and -1 is normal bone density. A Tscore between -1 and -2.5 indicates low bone density or osteopenia, and a T-score of -2.5 or lower is an osteoporosis according to WHO diagnostic criteria of Osteoporosis. ${ }^{9}$ The aim of this study was to test the bone mineral density among 30 years old and over in western Maharashtra and see the associations of bone mineral density with age, sex and menopause.

\section{Materials and Methods}

This were a cross sectional, descriptive study of 2400 subjects, who were either patients or relatives of patients coming to Gurukrupa Arogyadham, Islampur, in the year 2019. The Bone mineral density was tested using DXR method. DXR is a technique that uses automated image analysis of hand radiographs to estimate BMD. System calculates bone mass by measuring cortical thickness, bone width, number of pores and size of pores to find porosity. A subject chosen for BMD estimation, was informed about procedure to be carried out. Written consent was taken for the same. Demographic data of subject (Name, age, sex, residential address, and telephone number) was recorded. Subject's height, weight and birth date were recorded.

X-ray (AP view) of non-dominant hand of the subject was taken at $50 \mathrm{mAs}$ and $50 \mathrm{kv}$. Tube cassette distance was $40 \mathrm{cms}$. $\mathrm{X}$-ray was developed, fixed and dried. If non-dominant hand is fractured, X-ray of dominant hand was used. ${ }^{21}$ Subject's demographic data was entered in computer system having Pronosco Xposure V 2.0. X- ray of subject was put in Umax power look 1120 scanner and scanner was turned on. X-ray image was scanned, saved in software. Reports were generated and printed. The fundamental radiogrammetric methodology of the digital $x$ ray radiogrammetry (DXR) method is an automated segmentation of given diaphysis into cortical and medullary regions. This segmentation enables the measurement of an average cortical thickness and an average width of the bone over a given region of interest. For $1 \mathrm{~cm}$ length 118 individual measurements are taken. From the cortical thickness and outer width $\mathrm{W}$ of the bone a compound measurement named bone volume per area (VPA) is derived. To achieve the benefit of improved precision, the VPA analysis is applied to 3 middle metacarpals. Region of interest are highlighted. These regions are automatically detected by software and cannot be modified by operator. Porosity of bone is also measured. BMD is calculated by software. A Tscore between +1 and -1 is normal bone density. A T-score between -1 and -2.5 indicates low bone density or osteopenia, and a T-score of -2.5 or lower is an osteoporosis according to WHO diagnostic criteria of Osteoporosis. (38) Along with BMD we get the values of porosity $\mathrm{T}$-score and Z-score. Tscore means no. of standard deviation between the subject's BMD and the average of the reference population at the age of peak bone mass. Z- Score compares the subject to age related reference population. Results were entered into SPSS22 and analyzed and presented using percentages, means and standard deviation. Anova test was conducted to compare means and a $\mathrm{P}$ value of 0.05 was used for statistical significance. The study was conducted after obtaining IEC permission from IEC committee at Prakash institute of medical sciences and research institute, Islampur, Maharashtra.

\section{Results}

A total of 2400 subjects participated in the study, $1488(62 \%)$ were female and $912(38 \%)$ were male. Out of a total of 2004 subjects, 1008(42\%) had normal bone density. 928 (38.7\%) had osteopenia and 464 (19.3\%) had osteoporosis. Mean age among normal subjects was 49.5 years with standard deviation of 10.73 years. Mean age was highest among osteopenic subjects with 63.81 years and standard deviation of 9.88 years.

Table 1: Mean age and Bone mineral density among different groups $(\mathrm{N}=2400)$

\begin{tabular}{|c|c|c|c|c|c|c|c|c|c|c|}
\hline & & \multicolumn{3}{|c|}{ Normal (1008) } & \multicolumn{3}{|c|}{ Osteopenia (928) } & \multicolumn{3}{|c|}{ Osteoporosis (464) } \\
\hline & & $\begin{array}{l}\text { Male } \\
(496)\end{array}$ & $\begin{array}{c}\text { Female } \\
(512)\end{array}$ & Total & $\begin{array}{l}\text { Male } \\
(328)\end{array}$ & $\begin{array}{c}\text { Female } \\
(600)\end{array}$ & Total & $\begin{array}{c}\text { Male } \\
(\mathbf{8 8})\end{array}$ & $\begin{array}{c}\text { Female } \\
(376)\end{array}$ & Total \\
\hline $\begin{array}{l}\text { Mean Age and } \\
\text { (SD) (in years) }\end{array}$ & & 52.82 & 46.40 & $\begin{array}{l}49.56 \\
(10.7)\end{array}$ & 60.36 & 53.56 & $\begin{array}{l}55.96 \\
(11.7) \\
\end{array}$ & 63.81 & 63.30 & $\begin{array}{l}63.40 \\
(9.88) \\
\end{array}$ \\
\hline \multirow{7}{*}{$\begin{array}{l}\text { Mean Bone } \\
\text { mineral density } \\
\text { and (SD) in } \\
\text { age group (in } \\
\text { years) }\end{array}$} & $31-40$ & $\begin{array}{c}0.58 \\
(0.05) \\
\end{array}$ & $\begin{array}{c}0.57 \\
(0.04)\end{array}$ & $\begin{array}{c}0.57 \\
(0.04)\end{array}$ & $\begin{array}{c}0.50 \\
(0.06) \\
\end{array}$ & $\begin{array}{c}0.51 \\
(0.02) \\
\end{array}$ & $\begin{array}{c}0.51 \\
(0.03) \\
\end{array}$ & - & $\begin{array}{c}0.37 \\
(0.00) \\
\end{array}$ & $\begin{array}{c}0.37 \\
(0.00) \\
\end{array}$ \\
\hline & $41-50$ & $\begin{array}{c}0.57 \\
(0.04)\end{array}$ & $\begin{array}{c}0.56 \\
(0.04)\end{array}$ & $\begin{array}{c}0.56 \\
(0.04)\end{array}$ & $\begin{array}{c}0.50 \\
(0.03)\end{array}$ & $\begin{array}{c}0.49 \\
(0.06)\end{array}$ & $\begin{array}{c}0.49 \\
(0.05)\end{array}$ & $\begin{array}{c}0.41 \\
(0.00)\end{array}$ & $\begin{array}{c}0.44 \\
(0.03)\end{array}$ & $\begin{array}{c}0.43 \\
(0.03)\end{array}$ \\
\hline & $51-60$ & $\begin{array}{c}0.60 \\
(0.09) \\
\end{array}$ & $\begin{array}{c}0.54 \\
(0.02) \\
\end{array}$ & $\begin{array}{c}0.57 \\
(0.07) \\
\end{array}$ & $\begin{array}{c}0.47 \\
(0.06) \\
\end{array}$ & $\begin{array}{c}0.48 \\
(0.09) \\
\end{array}$ & $\begin{array}{c}0.47 \\
(0.08) \\
\end{array}$ & $\begin{array}{c}0.41 \\
(0.04) \\
\end{array}$ & $\begin{array}{c}0.38 \\
(0.05) \\
\end{array}$ & $\begin{array}{c}0.38 \\
(0.05) \\
\end{array}$ \\
\hline & $61-70$ & $\begin{array}{c}0.62 \\
(0.08)\end{array}$ & $\begin{array}{c}0.52 \\
(0.01)\end{array}$ & $\begin{array}{c}0.61 \\
(0.08)\end{array}$ & $\begin{array}{c}0.50 \\
(0.03)\end{array}$ & $\begin{array}{c}0.47 \\
(0.03)\end{array}$ & $\begin{array}{c}0.48 \\
(0.03)\end{array}$ & $\begin{array}{c}0.48 \\
(0.03)\end{array}$ & $\begin{array}{c}0.38 \\
(0.04)\end{array}$ & $\begin{array}{c}0.40 \\
(0.05)\end{array}$ \\
\hline & $71-80$ & $\begin{array}{c}0.59 \\
(0.08) \\
\end{array}$ & - & $\begin{array}{c}0.59 \\
(0.05)\end{array}$ & $\begin{array}{c}0.50 \\
(0.02)\end{array}$ & $\begin{array}{c}0.47 \\
(0.02) \\
\end{array}$ & $\begin{array}{c}0.49 \\
(0.03) \\
\end{array}$ & $\begin{array}{c}0.43 \\
(0.01) \\
\end{array}$ & $\begin{array}{c}0.38 \\
(0.04)\end{array}$ & $\begin{array}{c}0.39 \\
(0.04) \\
\end{array}$ \\
\hline & Total & $\begin{array}{c}0.59 \\
(0.08)\end{array}$ & $\begin{array}{c}0.56 \\
(0.03)\end{array}$ & $\begin{array}{c}0.57 \\
(0.06)\end{array}$ & $\begin{array}{c}0.49 \\
(0.04)\end{array}$ & $\begin{array}{c}0.48 \\
(0.06)\end{array}$ & $\begin{array}{c}0.48 \\
(0.06)\end{array}$ & $\begin{array}{c}0.44 \\
(0.04)\end{array}$ & $\begin{array}{c}0.38 \\
(0.04)\end{array}$ & $\begin{array}{c}0.39 \\
(0.04)\end{array}$ \\
\hline & $\begin{array}{c}\text { Sig. } \\
\text { (Anova) }\end{array}$ & $\begin{aligned} \mathrm{F} & =0.611 ; \mathrm{P} \\
& =0.656\end{aligned}$ & $\begin{array}{l}F=1.697 \\
P=0.177\end{array}$ & $\begin{aligned} \mathrm{F} & =1.211 ; \mathrm{P} \\
& =0.309\end{aligned}$ & $\begin{aligned} \mathrm{F} & =1.087 ; \mathrm{P} \\
& =0.378\end{aligned}$ & $\begin{aligned} \mathrm{F} & =0.970 ; \mathrm{P} \\
& =0.430\end{aligned}$ & $\begin{array}{c}\mathrm{F}=1.018 ; \mathrm{P}= \\
0.401\end{array}$ & $\begin{array}{c}\mathrm{F}=1.936 ; \mathrm{P}= \\
0.212\end{array}$ & $\begin{array}{l}F=1.661 \\
P=0.177\end{array}$ & $\begin{array}{l}F=1.065 \\
P=0.383\end{array}$ \\
\hline
\end{tabular}

Table No.1 shows Mean age and BMD among different groups $(\mathrm{N}=2400)$. Mean age was lower in normal subjects 45.5 years, with SD 10.7 years, compared to osteopenia subjects 55.9 years and osteoporosis subjects 63.4 years. Overall, BMD was higher in normal subjects compared to osteopenia and osteoporotic subjects (0.57 vs 0.448 and 0.39 ). BMD among normal subjects ranged from 0.52 to 0.57 , highest being in $31-40$ years 0.57 , with SD $0.05(\mathrm{~F}=1.211$; P
$=0.309)$. BMD was higher among males compared to females across all age groups of normal subjects. Among osteopenia subjects, BMD was BMD was similar in males and females. There was no statistically significant association between BMD and age groups both among males and females (Males $\mathrm{F}=1.087, \mathrm{P}=0.378$; Females $\mathrm{F}=0.970, \mathrm{P}=0.430)$ in osteopenia subjects.

BMD among osteoporotic subjects BMD was higher among 
males compared to females (0.48 vs 0.38$)$. There was no statistically significant association between BMD and age groups both among males and females (Males $\mathrm{F}=1.936 ; \mathrm{P}=$ 0.212 ; Females $\mathrm{F}=1.661 ; \mathrm{P}=0.177$ ) in osteoporotic subjects.

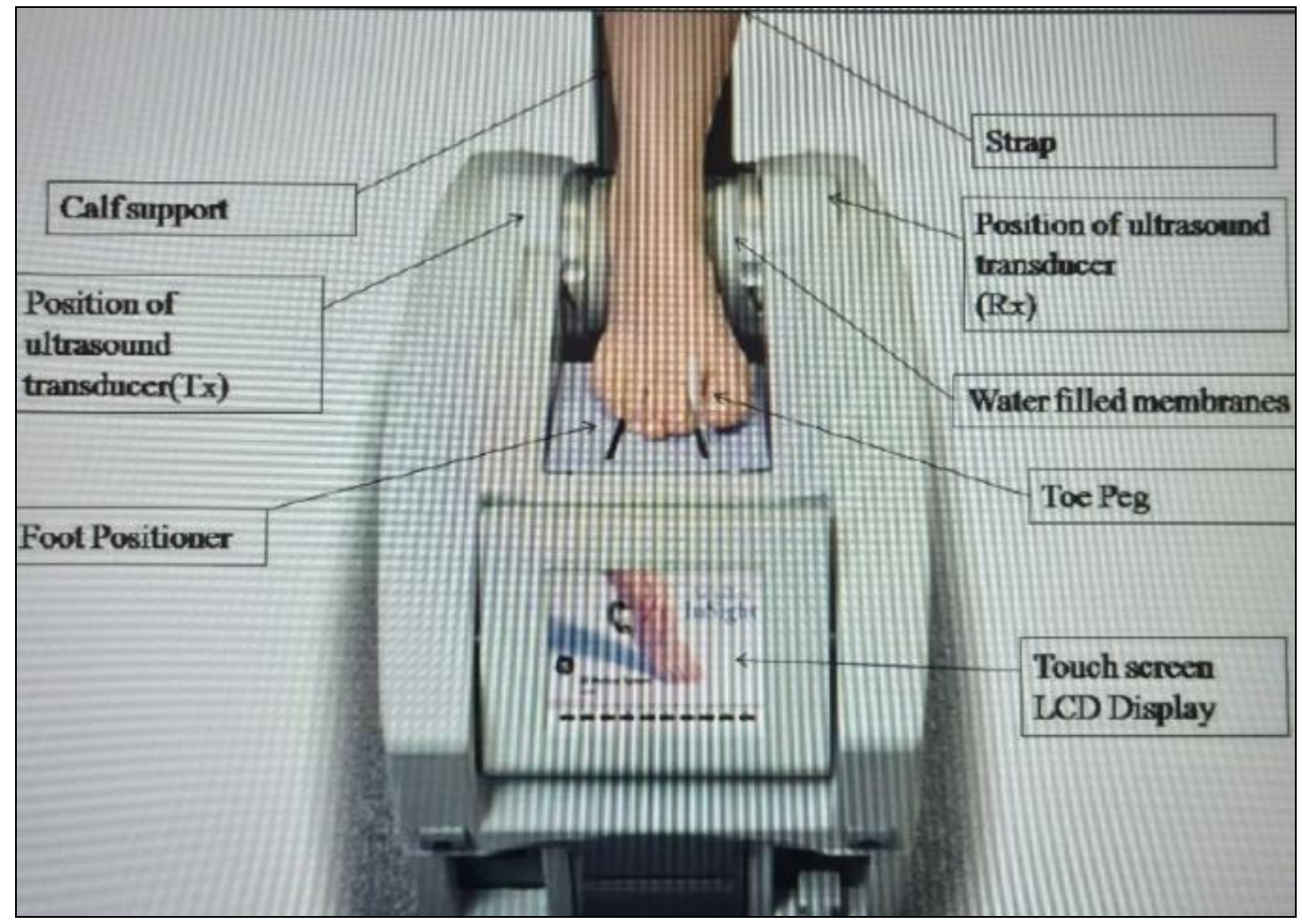

Fig 1: The working position and the components of the ultra-sonometer device

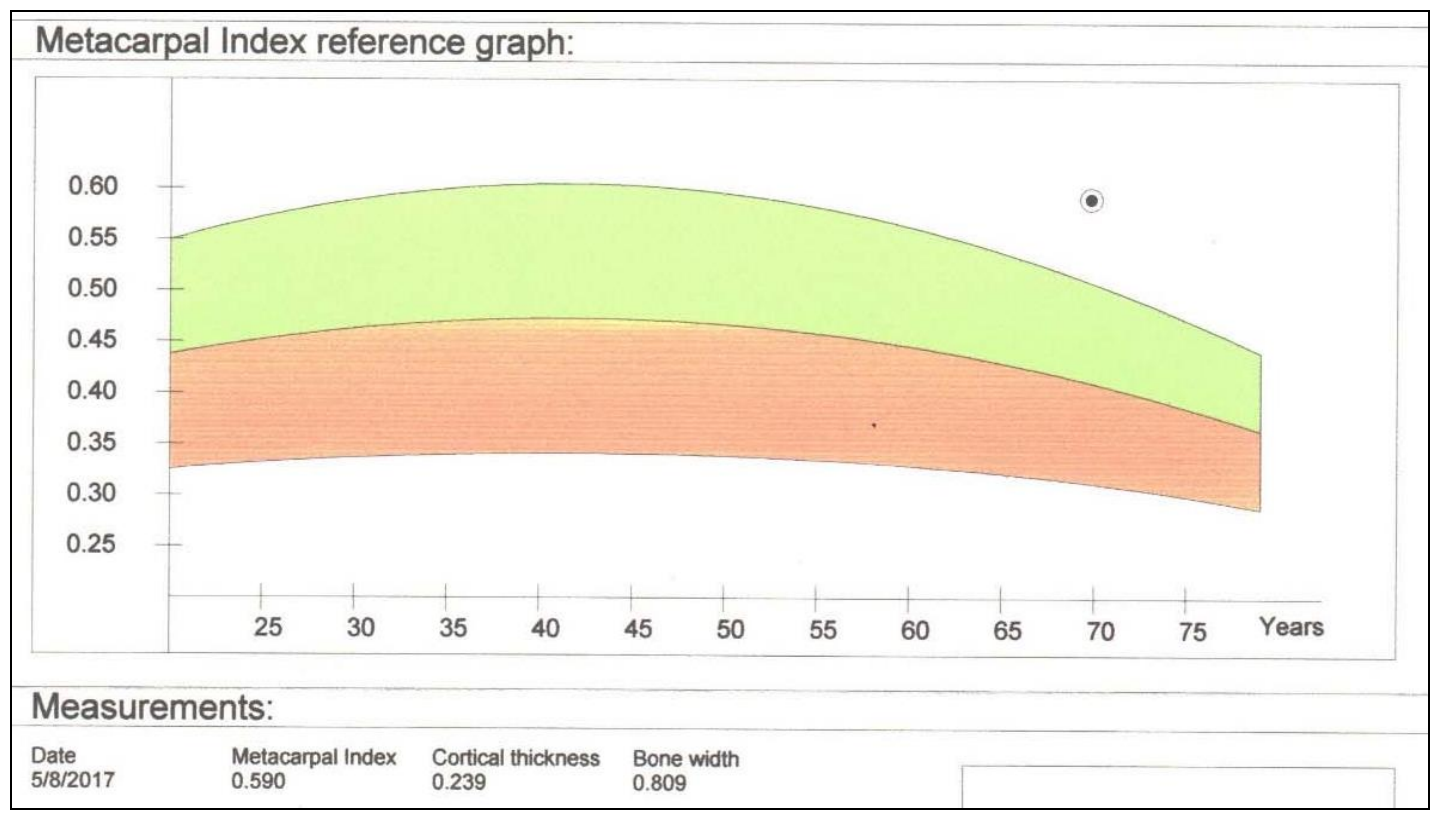

Fig 2: Metacarpal index reference graph of a subject.

\section{Discussion}

Measurement of BMD is the gold standard test for the diagnostic evaluation of osteoporosis. DXR is the method used in this study. Bone loss and associated fractures are increasingly recognized as a significant health problem in our aging population. The promising advances in finding effective treatment for accelerated bone loss have stimulated the search for a laboratory test to aid in the diagnosis of osteoporosis prior to the development of disabling fractures. Among the facture risk factors that have been identified during the past 30 years or so advancing age, low body weight, low mineral density, a history of fractures and falls are important. ${ }^{10-15}$
Digital X-ray of non-dominant hand is used in DXR technology. Main disadvantage of plain radiography is that about $50 \%$ of the bone minerals has to be lost before this demineralization becomes apparent on standard radiograph.

A study done in Mumbai on 200 women above 40 years of age evaluated BMD and $58 \%$ of the subjects were normal. This proportion is higher than that seen in our study (42\%). While the proportion of osteopenia subjects was similar in both studies, the proportion of osteoporotic subjects was higher in our study $(19.3 \%$ vs $8 \%)$. In both studies it was noted that the proportion of normal population decreased with advancing age-group ${ }^{[1]}$. 
The population in Western Maharashtra is more at risk as compared to population referred to in the study. In our study proportion of osteoporosis in 51 to 60 age group was $21.1 \%$ where as it was $25 \%$ for the age group 51 to 55 years in Mumbai study. Percentage of osteoporosis was higher in our study as our study was done in rural area. Population in our study was coming from low-income group. Dietary deficiencies, tobacco chewing, smoking and alcohol indulgence in males are common factors responsible for low BMD. Similarly, health consciousness in rural population is less as compared to urban population. No woman was found osteoporotic in the age group of 41-45 years in Mumbai study. But at the age of 56-60 years, proportion was $45.41 \%$ and above 60 years it was $100 \%$ in the study mentioned ${ }^{[1]}$. In our study, women in the age group 30-40 years group, the proportion of osteoporosis was $0.33 \%$. Only one woman was showing osteoporosis. So, we collected information about her history of medication and found that she was on steroids for 3 years. In 51-60 ears age-group number of osteoporotic women was 118 out of total 376. Osteoporotic women in Mumbai study were 4 out of 16 in age group 51-55years. Both studies showed that proportion of osteoporosis was remarkably high at the age 51-60, which is a postmenopausal age. In India osteoporosis was found to be in the ratio of $1: 1.5$ in men and women. In our study 88 males and 376 females were found to be the osteoporotic, so ratio is 1:4.2. This shows that osteoporosis is more in women than in men in Western Maharashtra ${ }^{[1]}$.

Mean BMD in all Males in our study is less than that seen in Mumbai study. This is because our study is in rural population where as in urban population good economic condition education as well as health consciousness play important role in maintaining good BMD ${ }^{[1]}$.

Normal Females are less as compared to Males. Osteopenic and Osteoporotic Female percentage is more than male. Bone loss after menopause is closely correlated to a decreasing level of Oestrogen. Oestrogen seems to protect against bone loss. After menopause oestradiol production drops to less than $10 \%$ of the premenopausal rate. Oestrogen now becomes the most important oestrogen. This may be one of the reasons why obese women are relatively protected from fractures after menopause ${ }^{[16]}$.

The DXR technology used in this study is based on a physical model of the bone ${ }^{[17]}$. BMD is estimated from geometrical measurements of the cortical thickness and the width of the bone, which are automatically conducted in a single anteriorposterior image of the hand. Following the suggestions of Meema, et al., and Bloom, et al., ${ }^{[18-19]}$ more than one bone is analysed (metacarpals 2 to 4 ) and the results are averaged to improve precision and accuracy. Compared to conventional radiogrammetry the computer based radiogrammetry implements a larger number of measuring points along the bone (118 points per centimeter). The measurement area (ROI) is fixed by the system in a predefined and not observer dependent manner. In contrast to Radioabsoptiometry, a standardized exposure is not necessary for the DXR technique [20].

In comparison with another study by $\mathrm{KC}$ Pande, et al., who examined 262 females and 178 males in two centers Nagpur and New Delhi. Plain radiographs of non-dominant hand were taken and analysis was performed by DXR method. Mean BMD of all women was 0.544 and S.D. 0.066 and the mean BMD of males was 0.586 and S.D. $0.054^{[20]}$.

An age dependent decrease in BMD was seen in both women and men. In conclusion the DXR BMD in Indian women is markedly lower than that in Indian men across the age group range. In all above studies BMD of men is more than BMD of women in corresponding age groups.

One major advantage of radiogrammetry measurements is that they can be performed on standard radiographs of the hand and forearm taken anywhere thereby giving the procedure wide availability. Furthermore, radiogrammetry is not influenced by beam hardening and is insensitive to soft tissue thickness ${ }^{[18]}$. However, similar to other peripheral bone densitometry technique, one potential disadvantage of radiogrammetry is that the measurements are not performed at the actual site of fracture. In estimating bone status from radiographs, radiogram metric parameters, except porosity, will not vary much and seem to be unaffected by variations in the X-ray source ${ }^{[19]}$.

In conclusion, as age advances percentage of subjects having normal BMD goes on decreasing and percentage of subjects having osteopenia and osteoporosis goes on increasing. Mean $\mathrm{BMD}$ in normal males of specific age group is more than mean BMD in normal females in the corresponding age group. Mean BMD of premenopausal females was more than postmenopausal females. Mean BMD in Females undergone Hysterectomy at whatever age was less than that of normal females of the same age group. Mean BMD in individuals having diseases like Rheumatoid Arthritis, Asthma, grarndmal epilepsy on treatment was less due interference of calcium absorption as well as calcium metabolism. This study gives appropriate picture of status of bone mineral density among population. It also gives exact prediction of bony fractures in the population. We can detect vulnerable population suffering Osteopenia or Osteoporosis and it will be easy to treat those people for the same in advance. Timely diagnosis and appropriate treatment reduce risk of bony fractures as well as economic load on individual person and ultimately on nation. It also reduces load over industries to compensate in terms of money and loss of man power.

\section{Source of funding: None}

\section{Conflict of Interest: None}

\section{Reference}

1. Gandhi AB, Shukla. AR. Evaluation of BMD of women above 40 years of age. $J$ Obstet Gynecol India. 2005;55(3):265-267.

2. E M Lewiecki, N B Watts. Assessing response to osteoporosis therapy Osteoporos Int 2008;19(10):1363-8.

3. Leslie WD, Pahlavan PS, Roe EB, Dittberner K. Bone density and fragility fractures in patients with developmental disabilities Osteoporos Int. 2009;20(3):379-83., DOI: 10.1007/s00198-008-0678-z.

4. Anagnostis P, Karagiannis A, Kakafika AI, Tziomalos K, Athyros VG, Mikhailidis DP. Atherosclerosis and osteoporosis: age-dependent degenerative processes or related entities? Osteoporos Int. 2009;20(2):197-207., DOI: 10.1007/s00198-008-0648-5. Epub 2008 May 29.

5. Von der Recke P, Hansen MA, Hassager C. The association between low bone mass at the menopause and cardiovascular mortality. Am J Med. 1999;106:273-278.

6. Mangiafico RA, AlagonaC, Pennisi P, Parisi N, Mangiafico M, Purrello F, et al. Increased augmentation index and central aortic blood pressure in osteoporotic postmenopausal women. Osteoporosis Int 2008;19:49-56.

7. Browner WS, Seeley DG, Vogt TM, Cummings SR. Non trauma mortality in elderly women with low bone 
mineral density. Study of Osteoporotic Fractures Research Group. Lancet. 2001;338:335- 358.

8. Krishna U, Mehta RU. Osteoporosis- incidence and implications. J Obstet Gynecol India. 2000:50:150-5.

9. Maggio D, Pacifici R, Cherubini A. Simonelli G. Luchetti M. Aisa MC, et al. Age-related cortical bone loss at the metacarpal. Calcif tissue Int. 1997;60:94-7.

10. Philadelphia. Elsevier/Churchill Livingstone. Standring S. Gray's Anatomy: The Anatomical Basis of Clinical Practice. Ed. 2018;39:94-97.

11. New Delhi. Jaypee Brothers Medical Publishers. Pushpalatha K, Bhat D, Pushpa NB. InderBir's Text book of Human Histology. Ed. 2018;3:104-108.

12. Philadelhia. Lippincott Williams and Wilkins, Weinstein SL(Ed), JBuckwalter JA (Ed). Turek's Orthopaedics: Principles and Their Application. Ed. 6:31-35.

13. Bone Morphogenetic protein. Wikipedia. Available at https://en.wikipedia.org/wiki/Bone_morphogenetic_prote in Accessed on 2018 Jan 25.

14. The India medicine central council act, 1970. Agreement of sections a Available at: https://legislative.gov.in/sites/default/files/A197048_0.pdf Accessed on 2018 Jan 25.

15. Maggio D, R Pacifici R, A Cherubini A, G Simonelli G, Luchetti M, Aisa MC, et al. Age-related cortical bone loss at the metacarpal. Calcif Tissue Int 1997;60(1):94-7.

16. Marshal D, Johnell O, Wendel H.Meta-analysisof how well measuresof bone mineral density predict occurrence of osteopotic fractures. BMJ. 1996:312:1254-1259.

17. Johneel O, Kanis JA, Oden A, Johanson H, De Laet C, Delmas $\mathrm{P}$, et al. Predictive value of BMD for hip and other fractures. J miner Res 2005:20:1185-1194.

18. Meema HE, Meindok $H$. Advantages of peripheral radiogrammetry over dual photon absorptiometry of the spine in the assessment of prevalence of osteoporotic vertebral fractures in women. JBMR. 1992;7:897-903.

19. Bloom RA. A comparative estimation of the combined cortical thickness of various bone sites. Skeletal Radiol. 1980;5:167-170.

20. Dey A, McCloskey E, Taube T, Cox R, Pande K, Ashford R, et al. Metacarpal morphometry using a semi automated technique in the assessment of osteoporosis and vertebral fracture risk. Osteoporosis Int. 2000;11:953-8. 